\title{
Ordering patterns for laboratory and radiology tests by students from different undergraduate medical curricula
}

Sigrid Harendza ${ }^{1 *}$, Lonneke Alofs², Jorike Huiskes ${ }^{2}$ and Marjo Wijnen-Meijer ${ }^{2}$

\begin{abstract}
Background: The overuse of laboratory tests and radiology imaging and their possible hazards to patients and the health care system is observed with growing concern in the medical community. With this study the authors wished to determine whether ordering patterns for laboratory and radiology tests by medical students close to their graduation are related to undergraduate training.
\end{abstract}

Methods: We developed an assessment for near graduates in the setting of a resident's daily routine including a consultation hour with five simulated patients, three hours for patient work up with simulated distracting tasks, and thirty minutes for reporting of patient management to a supervisor. In 2011, 60 students participated in this assessment: 30 from a vertically integrated (VI) curriculum (Utrecht, The Netherlands) and 30 from a traditional, non-VI curriculum (Hamburg, Germany). We assessed and compared the number of laboratory and radiology requests and correlated the results with the scores participants received from their supervisors for the facet of competence "scientifically and empirically grounded method of working".

Results: Students from a VI curriculum used significantly $(p<.01)$ less total laboratory requests $(N=283$ versus $N=466$ ) which correlated with their scores for a "scientifically and empirically grounded method of working" (Pearson's $r=.572)$. A significantly $(p<.01)$ higher number of radiology imaging was ordered with a large effect size $(V=.618)$ by near graduates from a non-VI curriculum ( $N=156$ versus $N=97$ ) even when this was not supporting the diagnostic process.

Conclusion: The focused ordering patterns from VI students might be a result of their early exposure to the clinical environment and a different approach to clinical decision making during their undergraduate education which further studies should address in greater detail.

Keywords: Laboratory test, Radiology test, Requesting pattern, Clinical reasoning, Competence, Differential diagnosis

\section{Background}

The overuse of laboratory tests and computer tomography (CT) remains a problem amongst physicians [1,2]. Two thirds of common laboratory investigations ordered during the hospitalisation of patients have no influence on management decisions [3]. Reasons for excessive ordering of tests by doctors include defensive behaviour and uncertainty, lack of experience, inadequate educational feedback,

\footnotetext{
* Correspondence: harendza@uke.de

1 Department of Internal Medicine, University Medical Centre HamburgEppendorf, Martinistr. 52, 20246 Hamburg, Germany

Full list of author information is available at the end of the article
}

and clinicians' unawareness about costs [4,5]. A study from Israel found that almost $70 \%$ of participating medical students did not receive any information about costs of medical tests during their undergraduate training [6]. A Belgian study revealed that physicians in an emergency department had limited knowledge of costs and radiation doses of the investigations they prescribed every day [7]. However, a combination of administrative changes and physician education initiatives can influence physicians' test-ordering behaviour [8]. Ordering guidelines or clinical guidelines can also alter the ordering patterns of

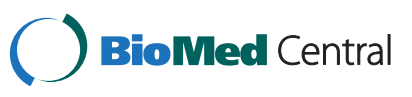


physicians and improve the appropriateness of laboratory tests and chest radiographs $[9,10]$.

A study from the early 90 s of the last century demonstrated that the medical history led to the final diagnosis in $76 \%$ of patients from an outpatient clinic while laboratory investigations did so in only $11 \%$ [11]. Additionally, medical students had difficulties selecting and justifying laboratory tests that would further narrow diagnostic possibilities and link the final diagnosis to the specific aspects of the history, physical examination and results of laboratory tests [12]. It has been assumed that making a diagnosis has shifted from the history and the physical examination to results of laboratory tests because faculty members are more often away from the bedside [13]. Therefore, case-based teaching of clinical reasoning has been proposed as a useful method to study the diagnostic process and to learn about the complex trade-offs between the benefits and risks of diagnostic tests [14].

Many medical schools have changed their undergraduate curricula to vertically integrated (VI) programmes to provide early clinical experiences and progressively increasing clinical responsibility [15-18]. This could ease the transition from student to doctor including the acquisition of clinical reasoning strategies and responsible ordering patterns for laboratory tests and radiology imaging. NonVI curricula equip students with many basic science facts and clinical details which they might try to apply in patient care [19]. VI curricula contain fewer details of basic science and clinical knowledge [20] which, on the other hand, might force students to apply different strategies of approaching a patient problem. Therefore, the research question of our study was: Do near graduates from a VI curriculum display a different ordering pattern for laboratory and radiology tests than near graduates from a nonVI curriculum and are these patterns associated with their respective competence score for a "scientifically and empirically grounded method of working"?

\section{Methods}

\section{Design and sample}

We developed and conducted a performance assessment for medical students near graduation named UHTRUST (Utrecht Hamburg Trainee Responsibility for Unfamiliar Situations Test) which is described and provided with a validity argument elsewhere [21,22]. In brief, voluntary participants were put in the position of beginning residents on a very busy day. First, each candidate had to see five standardized patients in an outpatient clinic (1 hour). Secondly, candidates were supposed to request additional information, e.g. laboratory tests, and to design examination or treatment schemes while confronted with seven realistic distracting tasks, e.g. questions from nurses (3 hours), and thirdly, candidates reported their differential diagnoses and management proposals for each patient to their supervising physicians (30 minutes).

Five patients presented with their respective problems: Case 1: 5 -year-old girl - case presented by her mother with weariness and abdominal pain (diagnosis: coeliac disease), case 2: 53-year-old man with haemoptysis and fatigue (diagnosis: Wegener's granulomatosis), case 3: 58-year-old woman with abdominal pain (diagnosis: perforated sigmoid diverticulitis), case 4: 65-year-old woman - accompanied by her husband - with difficulties to speak and to swallow (diagnosis: myasthenia gravis), case 5: 36-year-old man with rheumatoid arthritis and fever (diagnosis: varicella zoster infection).

All candidates were assessed on different facets of competence (FOCs) [23] by physicians, nurses and standardized patients. Sixty medical students near graduation participated during the assessment days in July and August 2011. At Utrecht University Hospital, a total of 30 near graduates (23 from Utrecht, 7 from Groningen) and at Hamburg University Hospital, 30 near graduates from Hamburg attended the assessment.

\section{Instruments and data collection}

Participants' performance was assessed regarding several FOCs with a set of different scoring forms described in further detail elsewhere [21]. The relevant instruments used for this particular study were the supervisors' ratings of the candidates regarding the FOC "scientifically and empirically grounded method of working" on a 3-point Likert scale of 1 (weak) to 3 (good). This FOC is described as follows: "The physician uses evidence-based procedures whenever possible and relies on scientific knowledge. He searches actively and purposefully for evidence and consults high quality resources. He uses his scientific knowledge critically and carefully in his work [23]".

Laboratory and radiology requests were counted for each candidate and country according to the following instructions. Participants from both countries used the typical ordering system of their training hospital. In Utrecht, candidates received regular, hospital adapted application forms for laboratory and radiology requests where they could mark the investigations they requested. In Hamburg, candidates were supplied with blank ordering forms where they could write in key words all investigations they wanted to order. Laboratory requests were counted in the following categories: "haematology", "clinical chemistry", "blood gas analysis", "clotting tests", "immunology", and "others". When Dutch participants, for example, asked for sodium, potassium and haemoglobin, they received one count for "clinical chemistry" and one count for "haematology". When German candidates, for example, asked for "blood count" the way it is usually done in their setting, they received one count for "haematology" even though the "blood count" includes haemoglobin, leukocytes, platelets, 
$\mathrm{MCH}$ and $\mathrm{MCV}$ which can all also be ordered individually. Radiology requests were counted in the categories "X-rays" and "CT-scans and other imaging".

\section{Statistical analysis}

We assessed differences between the candidate groups from both countries by $x^{2}$-tests regarding the number of laboratory or radiology requests within the different categories and in total for laboratory or radiology requests, respectively with significance levels of $\mathrm{p}<.05$. Effect sizes (Cramer's V) are also provided with values of .1 indicating small and values of $>.5$ indicating large effects. We calculated Pearson correlation coefficients ( $r$ ) between the mean score of two physicians for the FOC "scientifically and empirically grounded method of working" and the number of total laboratory and radiology requests.

\section{Ethical approval}

Ethical approval for the Dutch part of the study was obtained from the NVMO Ethical Review Board. For the German part, ethical approval was obtained from the State of Hamburg Physicians' Ethics Board. All subjects provided written informed consent to participate in the study.

\section{Results}

\section{Laboratory requests}

German candidates requested a significantly higher number of total laboratory tests $(\mathrm{p}<.01)$ with a large effect size $(\mathrm{V}=.754)$. The number of laboratory tests ordered individually for each of the five patients was also significantly higher $(\mathrm{p}<.05$ and $<.01$, respectively) for German candidates in all cases (Table 1). The number of total laboratory tests showed a significant correlation with the achieved score in the FOC "scientifically and empirically grounded method of working" for Dutch (Pearson's $\mathrm{r}=.572$ ) but not for German participants. The most prominent difference in laboratory test ordering patterns by Dutch and German candidates was found in the category "clotting test" (Table 1). For all individual patients and in total, German candidates ordered significantly more clotting tests compared with Dutch candidates ( $\mathrm{p}<.05$ and .01 respectively).

\section{Radiology requests}

A significantly higher number of radiology requests was made by German candidates (Table 1) compared with Dutch candidates $(\mathrm{p}<.01)$ with a large effect size $(\mathrm{V}=.618)$. No significant correlation was found for the total number of radiology requests and the score for the FOC "scientifically and empirically grounded method of working" in either country. Furthermore, German candidates requested more than twice as many CT-scans and other imaging compared with Dutch candidates $(\mathrm{p}<.01)$ (Table 1). The most significant difference $(\mathrm{p}<.001)$ was found for case 1 (5-year-old girl with weariness and abdominal pain) whereas no significant difference could be found for case 3 (58-year-old woman with perforated sigmoid diverticulitis).

\section{Discussion}

Near graduates from a VI curriculum (The Netherlands) ordered significantly less laboratory tests for the same patients they had to manage in this assessment compared with near graduates from a non-VI curriculum (Germany). A high number of laboratory requests was only associated with high scores for the FOC "scientifically and empirically grounded method of working" in participants from a VI curriculum. These findings support our hypothesis that students from a VI curriculum might apply different ways in approaching and managing patients. Early clinical experiences and involvement with patient care might shape students' diagnostic performances [24]. They use evidence-based laboratory test approaches such as testing only where it seems appropriate, knowing about the nature and quality of evidence required for the clinical utility of a test, and learning how a test result impacts on clinical actions [25]. Supporting this hypothesis further, it has been demonstrated in a Swedish study that fifth year medical students from a non-VI curriculum requested a significantly greater number of laboratory tests for a given number of primary health care cases than physicians undergoing postgraduate training in general medicine which was interpreted to reflect differences in clinical experience [19].

Table 1 Laboratory and radiology requests

\begin{tabular}{lcccc}
\hline $\begin{array}{l}\text { Patient } \\
\text { case }\end{array}$ & $\begin{array}{c}\text { Total laboratory request (n) } \\
\text { NL / G }\end{array}$ & $\begin{array}{c}\text { Requests for clotting tests }(\mathbf{n}) \\
\text { NL / G }\end{array}$ & $\begin{array}{c}\text { Total radiology requests (n) } \\
\text { NL / G }\end{array}$ & $\begin{array}{c}\text { Requests for CT scans (n) } \\
\text { NL / G }\end{array}$ \\
\hline $\mathbf{1}$ & $47 / 85^{* *}$ & $0 / 7^{* *}$ & $7 / 20^{* *}$ & $0 / 20^{* *}$ \\
$\mathbf{2}$ & $69 / 116^{* *}$ & $4 / 16^{* *}$ & $28 / 38$ & $4 / 11^{*}$ \\
$\mathbf{3}$ & $54 / 83^{* *}$ & $1 / 17^{* *}$ & $36 / 46$ & $24 / 25$ \\
$\mathbf{4}$ & $50 / 84^{*}$ & $0 / 8^{* *}$ & $7 / 19^{*}$ & $3 / 11^{*}$ \\
$\mathbf{5}$ & $63 / 98^{* *}$ & $4 / 12^{*}$ & $19 / 33^{* *}$ & $0 / 5^{*}$ \\
Total & $283 / 466^{* *}$ & $9 / 60^{* *}$ & $97 / 156^{* *}$ & $31 / 72^{* *}$ \\
\hline
\end{tabular}

$n$ number, NL The Netherlands, G Germany, ${ }^{*} \mathrm{p}<.05 ;{ }^{* *} \mathrm{p}<.01$. 
It has been shown for certain blood tests, e.g. uric acid, that physicians order these "out of habit" [26] which might have been the case for clotting tests by near graduates form the non-VI curriculum in Germany. For all patients in our setting, clotting tests were within normal range and according to the design of the patient cases neither a normal nor a pathological clotting test would have provided helpful information to support or to exclude a potential differential diagnosis. The fact, that the number of laboratory tests decreases with physicians' cumulative experience in caring for a patient's primary diagnosis [27] supports early clinical training for medical students as provided in VI curricula. Furthermore, clinical experience and clinical reasoning strategies facilitate estimation of the pre-test probability for a disease leading to the correct selection of laboratory tests [28]. To further improve and manage demands for laboratory tests a computerised laboratory management and reimbursement system based on diagnosistreatment combinations seems to be promising [29]. This could be a useful tool in undergraduate and postgraduate medical education to support patient management strategies and to lower unnecessary laboratory costs.

Radiology tests were also ordered to a significantly greater extent by near graduates from a non-VI curriculum. This difference was most prominent for CT scans where only one of the five patients in our study (case 3) would have needed a CT scan to confirm her diagnosis which was correctly ordered by most of the VI curriculum near graduates. A growing overutilization of radiology procedures at times when they will not improve diagnostic processes or patient outcomes has been noted in general [30]. Its potential hazard to patients by overexposing them to unnecessary radiation doses has been described [30]. A lack of certainty, confidence, or experience in the diagnosis has been identified as potential reasons for an overuse of imaging procedures [31]. Very worrisome is the fact that two thirds of participants from the non-VI curriculum in our study wanted to perform a CT scan in a 5-year-old child where this investigation would not have been necessary to work out the correct diagnosis. There is growing concern in the medical community about the increasing number of unnecessary CT scans, especially for children [32]. The use of CT scans in children with a cumulative dose about 50 to 60 mGy has recently been shown to be associated with an increased risk of leukaemia and brain cancer, respectively [33]. Physicians' unawareness of such radiation risks has been of major concern in recent years [34]. As for laboratory tests, a computerized radiology order entry system with decision support based on clinical reasoning strategies and utility scores on the indications was demonstrated to have an important impact on physicians' ordering practices [35]. Early clinical experiences and increasing responsibilities with feedback as provided in VI curricula in medical undergraduate education might have a similar effect.
We newly developed and validated [22] this prototypic assessment for medical graduates in a simulated realistic work situation. Furthermore, voluntary participants were not under the pressure of a real assessment situation and could behave "normally". On the other hand, because participation was voluntary only very motivated students might have participated which could challenge the results. Also, participants were not only near graduates from different types of medical curricula but also from different countries which might reflect certain cultural differences. Participants also used different techniques for their laboratory and radiology requests, simulating the system they were accustomed to in either country for best realistic performance. Furthermore, a more cost-conscience organizational culture in one country or possible variance in local strategies regarding laboratory ordering could account for portions of the variance observed. Even taking such biases into account, our results appear considerably unambiguous and apparent.

\section{Conclusions}

Our study shows that ordering patterns for laboratory tests correlate highly with the score for a "scientifically and empirically grounded method of working" in near graduates from a VI curriculum. These near graduates also order significantly less radiology tests than near graduates from a non-VI curriculum and use CT scans predominantly in situations when they are absolutely required in the diagnostic process. We conclude that students from a VI curriculum are trained to acquire laboratory and radiology test in a much more patient and diagnosis oriented way which might be a result of their early exposure to the clinical environment and their increasing clinical responsibility during undergraduate medical education. This should be addressed in further studies about clinical decision making.

\section{Abbreviations \\ $C T$ : Computer tomography; FOC: Facet of competence; MCH: Mean cell haemoglobin; MCV: Mean corpuscular volume; VI: Vertically integrated.}

\section{Competing interests}

The authors declare that they have no competing interests.

\section{Authors' contributions}

All authors have contributed sufficiently to the project to be included as authors: MWM and SH designed the study, JH acquired the data, LA performed the statistical analysis. SH and MWM drafted the manuscript. All authors read and approved the final manuscript.

\section{Acknowledgements}

No funding was received for this study.

\section{Author details}

'Department of Internal Medicine, University Medical Centre HamburgEppendorf, Martinistr. 52, 20246 Hamburg, Germany. ${ }^{2}$ Center for Research and Development of Education, UMC Utrecht, P.O. Box 85500, Utrecht, GA 3508 The Netherlands. 
Received: 1 November 2012 Accepted: 12 August 2013

Published: 14 August 2013

\section{References}

1. Winkens R, Dinant GJ: Evidence base of clinical diagnosis: rational, cost effective use of investigations in clinical practice. BMJ 2002, 324:783-785.

2. Miglioretti DL, Smith-Bindman R: Overuse of computed tomography and associated risks. Am Fam Physician 2011, 83:1252-1254.

3. Miyakis S, Karamanof G, Liontos M, Mountokalakis TD: Factors contributing to inappropriate ordering of tests in an academic medical department and the effect of an educational feedback strategy. Postgrad Med J 2006, 82:823-829.

4. Young DW: Improving laboratory usage: a review. Postgrad Med J 1988 64:283-289.

5. Hindemarsh JT, Lyon AW: Strategies to promote rational clinical chemistry test utilization. Clin Biochem 1996, 29:291-299.

6. Toker A, Reuveni H, Perry ZH, Doron Y: Medical students' knowledge and attitudes towards costs of tests and treatments. Harefuah 2007 146:22-25. 79. [Article in Hebrew].

7. Nougon G, Gerard V, Jamart J, Vanpee D: How aware are Belgian permanent and resident emergency physicians of common medical costs and radiation doses? Eur J Emerg Med 2011, 18:344-350.

8. Plapp FV, Essmyer CE, Byrd AB, Zucker ML: How to successfully influence laboratory test utilization. Clin Leadersh Manag Rev 2000, 14:253-260.

9. Sucov A, Bazarian JJ, deLahunta EA, Spillane L: Test ordering guidelines can alter ordering patterns in an academic emergency department. J Emerg Med 1999, 17:391-397.

10. Prat G, Lefèvre M, Nowak E, Tonnelier JM, Renault A, L'Her E, Boles JM: Impact of clinical guidelines to improve appropriateness of laboratory tests and chest radiographs. Intensive Care Med 2009, 35:1047-1053.

11. Peterson MC, Holbrook JH, von Hales D, Smith NL, Staker LV: Contributions of the history, physical examination, and laboratory investigation in making medical diagnoses. West J Med 1992, 156:163-165.

12. Connell KJ, Sinacore JM, Schmid FR, Chang RW, Perlman SG: Assessment of clinical competence of medical students by using standardized patients with musculoskeletal problems. Arthritis Rheum 1993, 36:394-400.

13. Sackett $\mathrm{DL}$, Rennie $\mathrm{D}$ : The science of the art of the clinical examination. JAMA 1992, 267:2650-2652.

14. Kassirer JP: Teaching clinical reasoning: case-based and coached. Acad Med 2010, 85:1118-1124.

15. Ten Cate O: Medical education in The Netherlands. Med Teach 2007, 29:752-757.

16. Cave J, Woolf K, Jones A, Dacre J: Easing the transition from student to doctor: how can medical schools help prepare their graduates for starting work? Med Teach 2009, 31:403-408.

17. Wijnen-Meijer M, Ten Cate OTJ, Van der Schaaf M, Borleffs JCC: Vertical integration in medical school: effect on the transition to postgraduate training. Med Educ 2010, 44:272-279.

18. Wijnen-Meijer M, ten Cate $O$, van der Schaaf M, Harendza S: Graduates from vertically integrated curricula. Clin Teach 2013, 10:155-159.

19. Andersson SI, Hovelius B, Tryding N: Decentralized laboratory testing: attitudes of physicians and medical students. Scand J Prim Health Care 1990, 8:197-202

20. Keijsers CJPW, Custers EJFM, Ten Cate OTJ: A new, problem oriented medicine curriculum in Utrecht: less basic science knowledge. Ned Tijdschr Geneeskd 2009, 153:1654-1659 [Article in Dutch].

21. Ohm F, Vogel D, Sehner S, Wijnen-Meijer M, Harendza S: Details acquired from medical history and patients' experience of empathy - two sides of the same coin. BMC Med Educ 2013, 13:67.

22. Wijnen-Meijer M, Van der Schaaf M, Booij E, Harendza S, Boscardin C, van Wijngaarden J, ten Cate TJ: An argument-based approach to the validation of UHTRUST: Can we measure how recent graduates can be trusted with unfamiliar tasks? Adv Health Sci Educ Theory Pract 2013 [Epub ahead of print].

23. Wijnen-Meijer $M$, van der Schaaf $M$, Nillesen $K$, Harendza S, ten Cate $O$ : Essential facets of competence that enable trust in graduate: A Delphi study among physician educators in the Netherlands. J Grad Med Educ 2013, 5:46-53

24. Noguchi Y, Matsui K, Imura H, Kivota M, Fukui T: A traditionally administered short course failed to improve medical students' diagnostic performance. A quantitative evaluation of diagnostic thinking. J Gen Intern Med 2004, 19:427-432

25. Price CP: Evidence-based laboratory medicine: supporting decision-making. Clin Chem 2000, 46:1041-1050.

26. Lohsoonthorn V, Dhanamum B, Williams MA: Prevalence of hyperuricemia and its relationship with metabolic syndrome in Thai adults receiving annual health exams. Arch Med Res 2006, 37:883-889.

27. Meltzer D, Manning WG, Morrison J, Shah MN, Jin L, Guth T, Levinson W: Effects of physicians experience on costs and outcomes on an academic general medicine service: results of a trial of hospitalists. Ann Intern Med 2002, 137:866-874.

28. Bergus GR, Chapman GM, Gjerde C, Elstein AS: Clinical reasoning about new symptoms despite pre-existing disease: sources of error and order effects. Fam Med 1995, 27:314-320.

29. Janssens PMW: Managing the demand for laboratory testing: options and opportunities. Clin Chim Acta 2010, 411:1596-1602.

30. Hendee WR, Becker GJ, Borgstede JP, Bosma J, Casarella WJ, Erickson BA, Maynard CD, Thrall JH, Wallner PE: Addressing overutilization in medical imaging. Radiology 2010, 257:240-245.

31. Sistrom CL, Dang PA, Weilburg JB, Dreyer KJ, Rosenthal DI, Thrall JH: Effect of computerized order entry with integrated decision support on the growth of outpatient procedure volumes: seven-year time series analysis. Radiology 2009, 251:147-155

32. Schenkman L: Second thoughts about CT imaging. Science 2011, 331:1002-1004.

33. Pearce MS, Salotti JA, Little MP, McHugh K, Lee C, Kim KP, Howe NL, Ronckers CM, Rajaraman P, Sir Craft AW, Parker L, Berrington de González A: Radiation exposure from CT scans in childhood and subsequent risk of leukaemia and brain tumours: a retrospective cohort study. Lancet 2012, 380:499-505.

34. Keijzers GB, Britton CJ: Doctors' knowledge of patient radiation exposure from diagnostic imaging requested in the emergency department. Med J Aust 2010, 18:450-453.

35. Rosenthal DI, Weilburg JB, Schultz T, Miller JC, Nixon V, Dreyer KJ, Thrall JH: Radiology order entry with decision support: initial clinical experience. J Am Coll Radiol 2006, 3:799-806.

\section{doi:10.1186/1472-6920-13-109}

Cite this article as: Harendza et al.: Ordering patterns for laboratory and radiology tests by students from different undergraduate medical curricula. BMC Medical Education 2013 13:109.

\section{Submit your next manuscript to BioMed Central and take full advantage of:}

- Convenient online submission

- Thorough peer review

- No space constraints or color figure charges

- Immediate publication on acceptance

- Inclusion in PubMed, CAS, Scopus and Google Scholar

- Research which is freely available for redistribution
C) Biomed Central 